\title{
INTERAÇÕES ENTRE AUXINAS E ÁCIDO BÓRICO, NO ENRAIZAMENTO DE ESTACAS CAULINARES DE Coffea arabica L. CV. MUNDO NOVO
}

\author{
E.O. ONO'; J.D. RODRIGUES'; S.Z. do PINHO ${ }^{3}$
}

RESUMO: O presente trabalho teve como finalidade, estudar o efeito de auxinas e do boro no enraizamento de estacas caulinares de Coffea arabica L. cr. "Mundo Novo". As estacas foram retiradas de ramos ortotropicos semi-lenhosos de cafeeiro, as quais foram tratadas durante 24 horas com soluçóes de IBA ou NAA e boro, e a mistura das tres substancias, resultando um total de 14 tratamentos. Para a avaliagão do objetivo em questão, foram realizadas as seguintes observaçós, mediante coleta ap6s 90 dias de plantio: número de estacas enraizadas e número de estacas com calos. Atraves dos resultados obtidos, pode-se concluir que, para obter um maior número de estacas enraizadas, é conveniente o tratamento com NAA a 100 ou 200 ppm mais boro.

Descritores: cafeeiro, estacas, enraizamento, boro, IBA e NAA.

\section{INTERACTIONS BETWEEN AUXINS AND BORIC ACID IN THE ROOTING OF STEM CUTTINGS Cofiea arabiea L. CV. "MUNDO NOVO"}

ABSTRACT: The present research had as purpose to study auxin and boron effects on rooting of Coffea arabica L. cv. "Mundo Novo" stem cuttings. The cuttings were taken from orthotropous semi-hardwood branches of coffee-tree, which were treated during 24 hours with IBA or NAA and boron solutions, and the mixture of the three substances, resulting a total of 14 treatments. The following observations were realized, taking the cuttings 90 days after planting: number of rooted cuttings and "callus" formation per cutting. It can be concluded that to obtain a higher number of rooted cuttings, the treatment with NAA at 100 or $200 \mathrm{ppm}$ plus boron is the most suitable.

Keg Words: coffee, cuttings, rooting, boron, IBA, NAA.

\section{INTRODUÇÃo}

A propagação de plantas, normalmente é realizada através de sementes; no entanto, por esse método não se tem a certeza de que o indivíduo formado, devido à recombinação gênica, mantém as mesmas características selecionadas das plantas parentais. Já na multiplicação de planta, por propagação vegetativa, obtem-se indivíduos com características geneticamente semelhantes as de seu progenitor. Segundo Wright (1964), citado por SILVA (1985), a

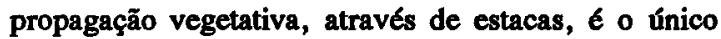
método de multiplicação de plantas cujo custo de execução pode competir com o da propagação por sementes.

O conhecimento de que o tratamento das estacas com auxinas, acelera e estimula a formação de raízes, vêm de longa data. Desde 1938, WENT observou em estacas de hipocótilo de ervilha, que 0 tratamento com auxina levou à aumentos no número de raízes formadas.

Dentre as auxinas mais utilizadas, podemos citar o ácido indol-acético (IAA), o ácido indol-butírico (IBA) e o ácido naftaleno-acético (NAA) (HARTMANN \& KESTER, 1983). Os mesmos autores afirmam que o IBA É, provavelmente, a melhor auxina, tendo em vista sua menor toxidez e sua eficácia no enraizamento de estacas de várias plantas.

A ação positiva das auxinas sobre o enraizamento das estacas, deve estar relacionada com a divisão das células que darão origem à raízes (HAISSIG, 1972). Além disso, estes hormônios levam ainda à sintese de RNA, o qual intervém na iniciação

\footnotetext{
${ }^{1}$ Bióloga, MSc, Departamento de Botânica-IB, Campus de Botucatu-UNESP. Botucatu-SP.

${ }^{2}$ Eng $^{\circ}$ Agr ${ }^{\circ}$, Professor Adjunto - Depto. Botânica-IB, UNESP. Botucatu-SP

${ }^{3}$ Enga Agra $^{2}$ Prof Adjunto. Depto. de Biestatística-IB. Campus de Botucatu-UNESP. Botucatu-SP
} 
do prim6rdio radicular (HESS, 1969), favorecendo a atividade metabólica, necessária para o desenvolvimento de novos tecidos de raiz, estimulando seu crescimento (ALTMAN, 1972; BREEN \& MURAOKA, 1973).

Além das auxinas, MIDDLETON et al., (1978), referem-se a necessidade de boro para o desenvolvimento dos primórdios radiculares e posterior crescimento das raizes, sendo fornecido em conjunto com a auxina ou posteriormente ao tratamento auxínico. Os mesmos autores, afirmam ainda, ser a iniciação das raízes estimulada pela auxina, sendo o subsequente crescimento das raízes dependente do fornecimento de boro ex6́geno.

LEWIS (1980), enfatiza um relacionamento metabólico no qual o boro, compostos fenólicos e peroxidases/IAA-oxidases interagem entre si e com as auxinas. A relação entre boro, auxina e atividade peroxidase/IAA-oxidase não está clara, existindo opiniões contraditórias. Por exemplo, a atividade da peroxidase é aumentada pela falta de boro em muitos tecidos (ODHNOFF, 1957), mas tem sua atividade diminuída em outros tecidos (DUTTA \& McILRATH, 1964). Além disso, a atividade da lAA-oxidase pode ser aumentada pelo boro (PARISH, 1968).

Assim os dados obtidos por JARVIS et al., (1983), em estacas de Phaseolus aureus Roxb., podem ser interpretados em termos do boro, aumentar direta ou indiretamente, a oxidação do IAA, portanto, diminuindo os níveis de auxinas efetivas; controlando dessa forma, as concentrações eficientes de auxinas no sítio de iniciação de raízes, permitindo o desenvolvimento e o crescimento destas.

Na cultura do cafeeiro, não é prática habitual, a propagação através de estacas, fato esse que se reflete na escassez de relatos na bibliografia especializada. No entanto, através de divulgação agronômica, sabe-se que esse procedimento está sendo realizado em pequena escala por firmas de reflorestamento, utilizando técnicas empregadas para obtenção de mudas de eucalipto.

Portanto, o objetivo deste trabalho, foi verificar a ação de auxinas e do boro, sobre o enraizamento de estacas caulinares de cafeeiro, seja para preencher lacunas existentes na literatura, como para auxiliar os produtores de mudas de café, através da estaquia.

\section{MATERIAL E MÉTODOS}

O presente trabalho foi conduzido em câmara de nebulização, do Departamento de Botânica, do Instituto de Biociências, do Campus de Botucatu, da Universidade Estadual Paulista, durante o ano de 1989.
Utilizaram-se ramos ortotrópicos semilenhosos de cafeeiro (Coffea arabica L. cv. "Mundo Novo"), contendo dois nós e duas folhas (FERNIE, 1940; INSTITUTO BRASILEIRO DO CAFÉ, 1986).

Após a confecção das estacas, suas bases foram mergulhadas, durante 24 horas, nas soluções aquosas contendo IBA e/ou NAA na concentração de 100 e 200 ppm (WEAVER, 1982), misturados ou não com ácido bórico à 150ug/ml (JARVIS et al., 1984). Das combinações entre auxinas e/ou boro, resultaram os seguintes tratamentos:

$$
\begin{aligned}
& \text {. T1 }\left(\mathrm{H}_{2} \mathrm{O}\right) \\
& \text {. T2 (IBA } 100 \mathrm{ppm} \text { ) } \\
& \text {. T3 (IBA } 200 \mathrm{ppm} \text { ) } \\
& \text {. T4 (IBA } 100 \mathrm{ppm}+\mathrm{B} \text { ) } \\
& \text {. T5 (IBA } 200 \mathrm{ppm}+\mathrm{B} \text { ) } \\
& \text {. T6 (NAA } 100 \mathrm{ppm} \text { ) } \\
& \text {. T7 (NAA } 200 \mathrm{ppm}) \\
& \text {. T8 (NAA } 100 \mathrm{ppm}+\mathrm{B} \text { ) } \\
& \text {. T9 (NAA } 200 \mathrm{ppm}+\mathrm{B} \text { ) } \\
& \text {. T10 (IBA } 100 \mathrm{ppm}+\text { NAA } 100 \mathrm{ppm}) \\
& \text {. T11 (IBA } 200 \mathrm{ppm}+\text { NAA } 200 \mathrm{ppm} \text { ) } \\
& \text {. T12 (IBA } 100 \mathrm{ppm}+\text { NAA } 100 \mathrm{ppm}+\mathrm{B} \text { ) } \\
& \text {. T13 (IBA } 200 \mathrm{ppm}+\mathrm{NAA} 200 \mathrm{ppm}+\mathrm{B} \text { ) } \\
& \text {. T14 (B) }
\end{aligned}
$$

Ap6s o tratamento das estacas, estas foram plantadas em bandejas de enraizamento, contendo vermiculita pura, e colocadas em câmara de nebulização durante 90 dias (PURUSHOTHAM \& ULLADMATH, 1985).

No intuito de verificar a ação das auxinas e do boro sobre o enraizamento de estacas caulinares de cafe, realizaram-se as seguintes medidas: número de estacas enraizadas e número de estacas com calos. Os resultados obtidos foram submetidos à análise de variância (teste F), sendo as médias comparadas através do teste Tukey.

\section{RESULTADOS E DISCUSSÃO}

\section{Número de Estacas Enraizadas}

Atraves da Tabela 1, pode-se verificar que os tratamentos que apresentaram maior número de estacas enraizadas foram: T8 (NAA $100 \mathrm{ppm}+\mathrm{B}$ ), T9 (NAA $200 \mathrm{ppm}+\mathrm{B}$ ), T5 (IBA $200 \mathrm{ppm}+\mathrm{B}$ ), T12 (IBA 100 ppm + NAA $100 \mathrm{ppm}+\mathrm{B}$ ) e T13 (IBA $200 \mathrm{ppm}+$ NAA $200 \mathrm{ppm}+$ B), todos constituídos por auxina mais boro. Foi observado ainda que, a adição de boro aos tratamentos auxínicos, incrementou o número de 
estacas enraizadas, sendo que o boro sozinho teve pouco efeito sobre esse parâmetro. Além disso, os resultados mostram que tratamentos onde houve a mistura de IBA e NAA, não foram mais efetivos que cada um separadamente; aparentemente o NAA foi mais efetivo que o IBA, no estímulo da formação de raízes.

WEISER (1959), trabalhando com estacas de Clematis,verificou que tratamentos realizados com IBA mais boro, estimularam o enraizamento, aumentando a porcentagem de estacas enraizadas, resultando em $85,6 \%$ de enraizamento contra $53,3 \%$ em estacas sem tratamento algum. Quando as estacas foram tratadas com boro ou auxina, sozinhos, a porcentagem de enraizamento foi $53,3 \%$ e $74,4 \%$, respectivamente, porcentagens menores que aquelas apresentadas por tratamentos com auxina mais boro. Ainda, DIRR \& FRETT (1983), trabalhando com estacas de Cupressocyparis leylandii tratadas apenas com boro, não mostraram alta porcentagem de enraizamento ou número de raízes, mas quando tratadas com IBA mais boro apresentaram sucesso no enraizamento. No mesmo ano, JARVIS et al. (1983), em estacas de Phaseolus aureus Roxb., observaram baixo desenvolvimento das raízes, quando as estacas foram tratadas apenas com IBA. Porém, quando ácido bórico foi fornecido juntamente com IBA, observou-se um aumento de quatro vezes no número de estacas enraizadas, em relação às estacas não tratadas.

Os dados obtidos neste trabalho, mostram que a adição de boro, aos tratamentos auxínicos, beneficiaram o enraizamento das estacas de cafeeiro, confirmando dessa forma, os resultados obtidos pelos autores acima citados.

Segundo SHEELAVANTAR et al. (1974), em estacas de algodão, tratamentos com IBA mais NAA, levaram a uma alta porcentagem de enraizamento, em relação àquelas tratadas com IBA ou NAA, separadamente, PURUSHOTHAM et al. (1984), também obtiveram alto número de estacas de Coffea canephora enraizadas, quando estas foram tratadas com IBA mais NAA, fato este não observado no presente trabalho.

DELARGY \& WRIGHT (1979), em estacas de macieira, e HINSELEY \& BLAZICH (1981), em estacas de Abies fraseri, verificaram ser o IBA mais efetivo que o NAA, no enraizamento dessas estacas. No entanto, PROEBSTING (1984), em estacas de Pseudotsuga menziensii, encontrou uma maior efetividade do NAA em relação ao IBA. Neste experimento, foi verificado que em estacas de cafeeiro, o NAA foi mais efetivo que o IBA, concordando com os resultados obtidos por PROEBSTING (1984). No entanto, a efetividade do IBA ou do NAA, no processo de enraizamento, é muito variada, sendo que algumas espécies respondem melhor ao IBA, e outras ao NAA.

TABELA 1. Análise de Variância (teste F) sobre os dados de número de estacas enraizadas, transformadas, transformados em raiz quadrada e comparação das médias pelo teste Tukey $(p<0,01)$.

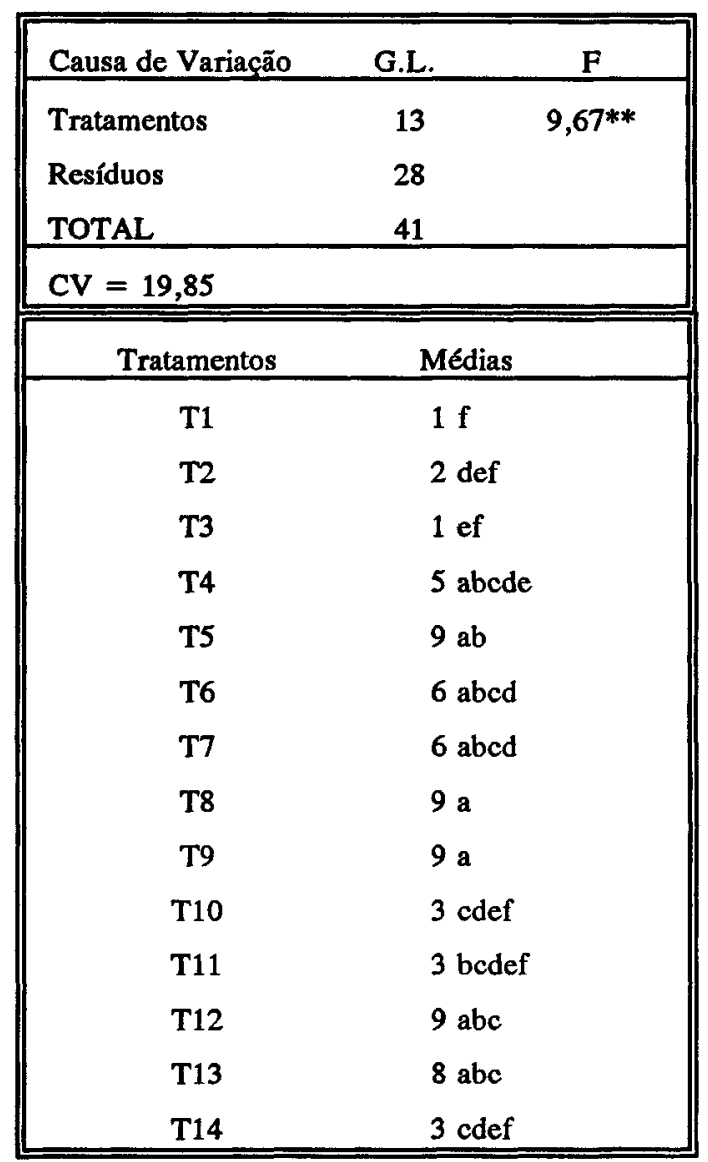

Médias seguidas de mesma letra, não diferem significativamente.

\section{Número de Estacas com Calo}

Na tabela 2, estão relacionados os dados referentes ao número de estacas com calos. Através dessa Tabela, pode-se observar que os tratamentos T1 $\left(\mathrm{H}_{2} \mathrm{O}\right)$, T2 (IBA $100 \mathrm{ppm}$ ), T11 (IBA $200 \mathrm{ppm}+\mathrm{NAA}$ 200 ppm) e T10 (IBA 100 ppm + NAA 100 ppm), 
foram aqueles que representaram o maior número de estacas com calos. Verificou-se ainda, que a adição de boro aos tratamentos auxínios, teve pouca influência na formação de calos sobre as estacas. Além disso, notouse uma melhor resposta ao IBA do que ao NAA, bem como maior número de estacas com calos em tratamentos com combinações de IBA e NAA, em relação àquelas tratadas com IBA ou NAA, separadamente.

TABELA 2. Análise de Variância (teste F) sobre os dados de número de estacas com calos, transformados em raiz quadrada $+0,5 \mathrm{e}$ comparação das médias pelo teste Tukey (p 0,01).

\begin{tabular}{||lll||}
\hline Causa de Variação & G.L. & F \\
\hline Tratamentos & 13 & $10,43 * *$ \\
Resíduos & 28 & \\
TOTAL & 41 & \\
\hline CV = 19,85 & \\
\hline \hline Tratamentos & Médias \\
\hline T1 & $15 \mathrm{a}$ \\
T2 & $13 \mathrm{ab}$ \\
T3 & $11 \mathrm{abc}$ \\
T4 & $11 \mathrm{cde}$ \\
T5 & $7 \mathrm{abcd}$ \\
T6 & $10 \mathrm{de}$ \\
T7 & $6 \mathrm{cde}$ \\
T8 & $7 \mathrm{cde}$ \\
T9 & $7 \mathrm{cde}$ \\
T10 & $12 \mathrm{ab}$ \\
T11 & $13 \mathrm{ab}$ \\
T12 & $7 \mathrm{cde}$ \\
T13 & $5 \mathrm{e}$ \\
T14 & $9 \mathrm{bcde}$ \\
\hline
\end{tabular}

Médias seguidas de mesma letra, não diferem significativamente.
REAÑo (1940), observou intensa formação de calos, nas estacas de cafeeiro tratadas com auxinas, quando comparadas àquelas sem tratamento, fato este confirmado por STRUCKMEYER (1951), que afirmou que as auxinas, através de uma estimulação da atividade cambial, leva à intensa formação de calos nas estacas. Carrera Garcia (1977), citado por SILVA (1985), afirma ser o calo uma formação regenerativa que ocorre, principalmente, pelo estímulo da atividade cambial e, muitas vezes, a formação do calo não está relacionada com a formação de raízes, uma vez que são processos fisiológicos independentes.

Neste trabalho, foi observado que os calos formados,sobre as estacas de cafeeiro, não se diferenciam em raízes, concordando com o relato anterior; portanto, pode-se afirmar que, não é interessante, em cafeeiro, a alta formação de calos.

\section{CONCLUSÃO}

Pode-se concluir que, para obter um maior número de estacas enraizadas e, consequentemente, maior formação de mudas de cafeeiro, o tratamento com NAA à 100 ou 200 ppm mais boro, tem efeito positivo sobre o processo de enraizamento.

\section{REFERÊNCIAS BIBLIOGRÁFICAS}

ALTMAN, A. The role of auxin in root initiation in cutting. Proceedings of international Plant Propagation Society, London, 22: 280, 1972.

BREEN, P. J. \& MURAOKA, T. Effect of indolebutyric acid on distribution of (14)Cphotosinthate in softwood cutting of Marianna 2624 Plum. Journal of American Society for Horticultural Science, Alexandria, 98: 436-9, 1973.

DELARGY, J.A.\& WRIGHT, C.E. Root formation in cutting of apple in relation to auxin application and to etiolation. New Phytologist, Cambridge, 82: 341-7, 1979.

DIRR, M.A. \& FRETT, J.J. Rooting Leyland cypress as affected by indolebutyric acid and boron treatment. HortScience, Alexandria, 18: 204-5, 1983.

DUTTA, T.R. \& McILRATH, W.J. Effects of boron on growth and lignification in sunflower tissue. Botanical Gazette, Chicago, 125: 89, 1964. 
FERNIE, L.M. The rooting of softwood cuttings of Coffea arabica. East African Agricultural Journal, Nairobi, 5: 323-9, 1940

HAISSIG, B.E. Meristematic activity during adventitious root primordium development influences of endogenous auxin and applied gibberellic acid. Plant Physiology, ethesda, 49: 886-92, 1972.

HARTMANN, H.T. \& KESTER, D.E. Plant Propagation: principles, and practices, 4.ed. New York, Englewood Clipps, 1983. 727p.

HESS, C.E. Internal and external factors regulating root initiation; root growth. 2 ed. London, Buttersworth, 1969. p. 42-53.

HINSELEY,L.E. \& BLAZICH, F.A. Influence of severance treatments on the rooting capacity of Fraser-fir stem cuttings. Canadian Journal of Forest Research, Ottawa, 11: 316-23, 1981.

INSTITUTO BRASILEIRO DO CAFÉ. Estaca dá susto. Globo Rural, Rio de Janeiro, 4: 8, 1986.

JARVIIS, B.C.; ALI, A.H.N.; SHAHEED, A.I. Auxin and boron in relation to the response and ageing on mung bean cuttings. New Phytologist, Cambridge, 95: 509-18, 1983.

JARVIS, B.C.; YASMIN, S.; ALI, A.H.N.; HUNT, $R$. The interaction between auxin and boron in adventitions root development. New Phytologist. Cambridge, 97: 197-204, 1984.

LEWIS, D. H. Boron, lignification and the origin of vascular plants a unified hypothesis. New Phytologist, Cambridge, 84: 209-29, 1980.

MIDDLETON, W.; JARVIS, B.C.; BOOTH,A. The boron requirement for rot development in stem cuttings of Phaseolus aureus oxb. New Phytologist, Cambridge, 81: 287, 1978.

ODHNOFF, C. Boron deficiency and growth. Physiologia Plantarum, Copenhagem, 10: 984$1000,1957$.

PARISH, R.W. In vitro studies on the relationship between boron and peroxidase. Enzymologia, Dordrecht, 35: 239-52, 1968.
PROEBSTING, W.M.. Rooting of Douglas-fir stem cuttings: relative activity of IBA and NAA. HortScience, Alexandria, 19: 854-6, 1984.

PURUSHOTHAM, K.\& SULLADMATH, U.V. Studies on the rooting of invigorated sucker cuttings of coffe. Journal of Coffee Research, Balehonnur, 15: 21-8, 1985.

PURUSHOTHAM, K.; SULLADMATH, U.V.; RMAIAH, P.K. Seasonal changes in biochemical constituints and their relation to rooting of coffee (Coffea canaphora Pierre) sucker cuttings. Journal of Coffee Research, Balehonnur, 14: 117-30, 1984.

REAÑO, P.C. Histological study and observations on the effects of some synthetic growth substances on stem tip cuttings of coffee. Philippine Agriculturist, Laguna, 29: 87-99, 1940.

SHEELAVANTAR, M.N.; PRABHAKAR, A.S.; PATIL, S.V. Preliminary studies on the propagation of cotton hybrids through cuttings. Current Research, Bangalore, 3: 95-6, 1974.

SILVA, I.C. Propagação vegetativa: aspectos morfofisiologicos. Itabuna, CEPLAC, 1985. 26p. (Boletim Técnico, 4)

STRUCKMEYER, E.S. Comparative effects of growth substances on stem anatomy. In: SKOOG, F. Plant growth substances. Wisconsin, University of Wisconsin, 1951. p. 167-74.

WEAVER, R.J. Reguladores del crescimiento en la agricultura. 2ed. Barcelona, Trillas, 1982. 540p.

WEISER, C. J. Effect of boron on the rooting of Clematis cuttings. Nature, London, 183: 559, 1959.

WENT, F.W. Synegistic factors other than auxin affecting growth and root formation. Plant Physiology, Bethesda, 13: 55-80, 1983.

Trabalho entregue para publicação em 25.09.91

Trabalho aprovado para publicação em 20.01.92 